\title{
Rethinking the duration requirement for generalized anxiety disorder: evidence from the National Comorbidity Survey Replication
}

\author{
RONALD C. KESSLER ${ }^{1 *}$, NANCY BRANDENBURG ${ }^{2}$, MICHAEL LANE ${ }^{1}$, \\ PETER ROY-BYRNE ${ }^{3}$, PAUL D. STANG ${ }^{4}$, DAN J. STEIN ${ }^{5}$ \\ AND HANS-ULRICH WITTCHEN
}

${ }^{1}$ Department of Health Care Policy, Harvard Medical School, Boston, MA, USA $;{ }^{2}$ Pfizer, Inc., New York, NY, USA $;^{3}$ Department of Psychiatry and Behavioral Sciences, University of Washington School of Medicine, Seattle, WA, USA $;{ }^{4}$ Department of Public Health, West Chester University, and Galt Associates, Blue Bell, PA, USA $;{ }^{5}$ Department of Psychiatry, University of Stellenbosch, Cape Town, South Africa $;{ }^{6}$ Institute of Clinical Psychology and Psychotherapy, Technical University of Dresden, Dresden, Germany

\begin{abstract}
Background. The proposed revisions of the ICD and DSM diagnostic systems have led to increased interest in evaluation of diagnostic criteria. This report focuses on the DSM-IV requirement that episodes of generalized anxiety disorder (GAD) must persist for at least 6 months. Community epidemiological data are used to study the implications of changing this requirement in the range 1-12 months for estimates of prevalence, onset, course, impairment, co-morbidity, associations with parental GAD, and sociodemographic correlates.
\end{abstract}

Method. Data come from the US National Comorbidity Survey Replication (NCS-R), a US household survey carried out during 2001-2003. Version 3.0 of the WHO Composite International Diagnostic Interview (WMH-CIDI) was used to assess DSM-IV anxiety disorders, mood disorders, substance disorders, and impulse-control disorders.

Results. Lifetime, 12-month, and 30-day prevalence estimates of DSM-IV GAD changed from $6 \cdot 1 \%, 2 \cdot 9 \%$, and $1 \cdot 8 \%$ to $4 \cdot 2-12 \cdot 7 \%, 2 \cdot 2-5 \cdot 5 \%$, and $1 \cdot 6-2 \cdot 6 \%$ when the duration requirement was changed from 6 months to 1-12 months. Cases with episodes of 1-5 months did not differ greatly from those with episodes of $\geqslant 6$ months in onset, persistence, impairment, co-morbidity, parental GAD, or sociodemographic correlates.

Conclusions. A large number of people suffer from a GAD-like syndrome with episodes of $<6$ months duration. Little basis for excluding these people from a diagnosis is found in the associations examined here.

\section{INTRODUCTION}

The minimum duration requirement for generalized anxiety disorder (GAD) was 1 month when GAD was introduced in DSM-III (APA,

\footnotetext{
* Address for correspondence: R. C. Kessler, Ph.D., Department of Health Care Policy, Harvard Medical School, 180 Longwood Avenue, Boston, MA, USA 02115.

(Email: kessler@hcp.med.harvard.edu)

The views and opinions expressed in this report are those of the authors and should not be construed to represent the views of any of the sponsoring organizations, agencies, or U.S. Government.
}

1980). However, clinical studies found that DSM-III GAD seldom occurred in the absence of other co-morbid anxiety or mood disorders (Breier et al. 1985; Breslau, 1985), suggesting that GAD might better be conceptualized as a prodrome, residual, or severity marker than an independent disorder (Breslau \& Davis, 1985b; Clayton et al. 1991; Noyes et al. 1992). Based on clinical evidence that co-morbidity substantially decreased with episode duration (Breslau \& Davis, 1985a), GAD was retained in DSM-III-R 
with an increased duration requirement of 6 months (APA, 1987). This change also addressed the problem of distinguishing short episodes of GAD from situational stress reactions (Barlow \& Wincze, 1998). A requirement that 'unrealistic, hard to control worry' be present was also included in DSM-III-R to sharpen the distinction between GAD and non-specific distress associated with other anxiety and mood disorders (Barlow et al. 1986). The ICD-10 criteria for research also require a 6-month duration (WHO, 1993), but the ICD-10 criteria for clinical practice take a middle position on duration by requiring GAD to last 'several months' (WHO, 1992).

This variation in required duration could dramatically influence the number of people classified with GAD. Contrary to the motivation for increasing the DSM-III-R duration requirement, epidemiological data have subsequently shown that GAD is not more co-morbid than most other anxiety or mood disorders (Kessler et al. 2001, 2004b) and that the extremely high co-morbidity of GAD in early clinical studies was due to a help-seeking bias (Wittchen et al. 1994). The 6-month duration requirement was nonetheless retained in DSM-IV (APA, 1994), which means that episodes of shorter duration receive no diagnosis even if they recur over many years. It has been suggested that such 'orphaned' cases of GAD are substantial in number (Rickels \& Rynn, 2001).

Three large community epidemiological studies examined whether episodes of GAD with durations of less than 6 months might either be less impairing (Maier et al. 2000) or less co-morbid with other DSM disorders (Bienvenu et al. 1998; Carter et al. 2001) than episodes lasting more than 6 months. No significant differences were found in any of these studies. One of these three papers (Bienvenu et al. 1998) also examined and found little variation in profiles of demographic correlates of DSM-III-R GAD with required episode duration. The current report builds on these earlier studies by presenting data from a nationally representative US household sample on the relationship between required GAD episode duration in the range 1-12 months and a wider range of correlates: onset, course, impairment, co-morbidity, parental GAD, and sociodemographics.

\section{METHOD}

\section{Sample}

Data come from the National Comorbidity Survey Replication (NCS-R) (Kessler et al. 2003; Kessler \& Merikangas, 2004), a face-toface survey $(n=9282)$ of the US household population conducted during 2001-2003. A multi-stage clustered area probability sampling design was used to select the sample (Kessler et al. 2003, 2004a). The response rate was $70 \cdot 9 \%$. Recruitment began with a letter and study fact brochure followed by an in-person interviewer visit to explain study aims and procedures. Verbal rather than written consent was used to be consistent with the baseline NCS (Kessler et al. 1994). Respondents received $\$ 50$. The human subjects committees of Harvard Medical School and the University of Michigan both approved these procedures.

All respondents were administered a Part I diagnostic interview (described below), while a probability subsample of 5692 respondents also received a Part II interview. Part II respondents included all who met lifetime criteria for any Part I disorder plus a probability sample of other respondents. The Part I sample was weighted to adjust for differential probabilities of selection within households and for differences in intensity of recruitment effort among hard-to-recruit cases. The Part II sample was additionally weighted for differential selection probabilities from Part I. A final weight adjusted the sample to match the 2000 census population on geographic and sociodemographic variables. All analyses reported here employ these weights. More complete information on NCS-R sampling design and weighting is reported elsewhere (Kessler et al. 2004a).

\section{Diagnostic assessment}

NCS-R diagnoses are based on Version 3.0 of the WHO Composite International Diagnostic Interview (CIDI) (Kessler \& Ustun, 2004), a fully structured lay-administered interview that generates diagnoses according to both ICD-10 (WHO, 1993) and DSM-IV criteria. DSM-IV criteria are used in the current report. The diagnoses include anxiety disorders, mood disorders, substance disorders, and a group of disorders that share a common feature of difficulties with impulse control (intermittent 
explosive disorder and three retrospectively reported childhood-adolescent disorders oppositional-defiant disorder, conduct disorder, and attention-deficit hyperactivity disorder). Diagnostic hierarchy rules and organic exclusion rules were used in making diagnoses. As detailed elsewhere (Kessler et al. in press), blind clinical re-interviews using the Structured Clinical Interview for DSM-IV (SCID; First et al. 2002) with a probability subsample of NCS-R respondents found generally good concordance between DSM-IV diagnoses based on the WMH-CIDI and the SCID for anxiety, mood, and substance use disorders. WMHCIDI diagnoses of impulse-control disorders were not validated. Concordance between CIDI and SCID diagnoses of GAD was good (AUC $0 \cdot 83$; OR $51 \cdot 0,95 \%$ CI $11 \cdot 5-226 \cdot 2$ ).

As the assessment of episode duration plays a central part in the following analyses, it is important to understand this assessment in CIDI 3.0. After inquiring about episodes of worry or anxiety with associated symptoms that lasted at least 1 month, the word 'episode' is explicitly defined: "When I use the word "episode" in the next question, I mean a time lasting 1 month or longer when most days you were (worried/ nervous or anxious/anxious or worried) and also had some of the other problems we just reviewed. The episode ends when you no longer have these feelings for a full month.' After providing this definition, respondents are asked about 12-month prevalence and then about number of lifetime episodes. Depending on number of episodes reported, maximum duration is then assessed by asking 'How long did that episode last?' or 'How long did the longest of these episodes last?' Responses presumably overestimate duration because episodes are defined as not ending until there is a full month without any symptoms rather than a month when symptoms occurred fewer than half the days.

\section{Other measures}

Three other sets of measures used here are role impairment, parental GAD, and sociodemographics. Role impairment among 12-month cases was assessed in two ways. First, respondents were asked the number of days in the past year they were 'totally unable' to carry out their daily activities because of their GAD. Second, respondents were administered the Sheehan Disability Scales (Leon et al. 1997), 0-10 visual analogue scales that ask respondents to focus on the one month in the past year when their GAD was most severe and to rate how much GAD interfered with their home management, work, social life, and personal relationships. The scales include response options of none (0), mild (1-3), moderate (4-6), severe (7-9), and very severe (10). Parental history of GAD was assessed with questions developed to expand the Family History RDC interview (Andreasen et al. 1977) to include GAD (Kendler et al. 1997). Sociodemographic correlates include gender, age at interview, race-ethnicity, education, marital status, employment status, and region.

\section{Analysis methods}

Prevalence was estimated using the minimum duration requirements $1,3,6$, and 12 months as well as using mutually exclusive subgroups with durations of $1-2,3-5,6-11$, and $\geqslant 12$ months. The actuarial method (Halli et al. 1992) was used to calculate age-of-onset curves for mutually exclusive duration subgroups. Means were calculated in these same subgroups for various measures of illness severity and course. Logistic regression analysis was used to examine variation across these subgroups in associations of lifetime GAD with co-morbid DSM-IV disorders, parental history of GAD, and sociodemographic variables. Standard errors and significance tests were obtained using the Taylor series linearization method (Wolter, 1985) implemented in the SUDAAN software package (Research Triangle Institute, 2002) to adjust for weighting and clustering. Multivariate significance was evaluated using Wald $\chi^{2}$ tests based on Taylor series design-based coefficient variance-covariance matrices. Statistical significance was evaluated at the 0.05 level with two-sided tests.

\section{RESULTS}

\section{Prevalence, onset, and course}

Lifetime GAD prevalence estimates range from $4.2 \%$ (12-month minimum duration requirement) to $12 \cdot 7 \%$ (1-month minimum duration requirement) (Table 1). The range of prevalence estimates is more narrow, but still substantial, for estimates of 12-month $(2 \cdot 2-5 \cdot 5 \%)$ and 
Table 1. Lifetime, 12-month, and 1-month prevalence estimates of DSM-IV generalized anxiety disorder by variation in required minimum episode duration and in maximum episode duration $(n=9282)^{\mathrm{a}}$

\begin{tabular}{|c|c|c|c|c|c|c|}
\hline & \multicolumn{2}{|c|}{ Lifetime } & \multicolumn{2}{|c|}{12 months } & \multicolumn{2}{|c|}{1 month } \\
\hline & $\%$ & (S.E.) & $\%$ & (S.E.) & $\%$ & (S.E.) \\
\hline \multicolumn{7}{|c|}{$\begin{array}{l}\text { I. Required minimum } \\
\text { episode duration }\end{array}$} \\
\hline 1 month & $12 \cdot 7$ & $(0 \cdot 5)$ & $5 \cdot 5$ & $(0 \cdot 3)$ & $2 \cdot 6$ & $(0 \cdot 2)$ \\
\hline 3 months & $8 \cdot 0$ & $(0 \cdot 4)$ & $3 \cdot 9$ & $(0 \cdot 2)$ & $2 \cdot 1$ & $(0 \cdot 2)$ \\
\hline 6 months & $6 \cdot 1$ & $(0 \cdot 3)$ & $2 \cdot 9$ & $(0 \cdot 2)$ & $1 \cdot 8$ & $(0 \cdot 2)$ \\
\hline 12 months & $4 \cdot 2$ & $(0 \cdot 2)$ & $2 \cdot 2$ & $(0 \cdot 1)$ & $1 \cdot 6$ & $(0 \cdot 2)$ \\
\hline \multicolumn{7}{|c|}{$\begin{array}{l}\text { II. Maximum } \\
\text { episode duration }\end{array}$} \\
\hline $1-2$ months & $4 \cdot 7$ & $(0 \cdot 2)$ & $1 \cdot 6$ & $(0 \cdot 2)$ & $0 \cdot 5$ & $(0 \cdot 1)$ \\
\hline $3-5$ months & 1.9 & $(0 \cdot 2)$ & $1 \cdot 0$ & $(0 \cdot 1)$ & $0 \cdot 3$ & $(0 \cdot 0)$ \\
\hline 6-11 months & 1.9 & $(0 \cdot 2)$ & $0 \cdot 8$ & $(0 \cdot 1)$ & $0 \cdot 2$ & $(0 \cdot 1)$ \\
\hline$\geqslant 12$ months & $4 \cdot 2$ & $(0 \cdot 2)$ & $2 \cdot 2$ & $(0 \cdot 1)$ & 1.6 & $(0 \cdot 2)$ \\
\hline
\end{tabular}

a Defined using DSM-IV criteria with organic exclusion and diagnostic hierarchy rules, but varying the duration requirement for the longest episode.

1-month $(1 \cdot 6-2 \cdot 6 \%)$ prevalence. The ratio of 12 -month to lifetime prevalence, an indirect indicator of persistence, varies significantly with required duration, from $51 \cdot 1 \%$ for 12 -month minimum duration to $43.3 \%$ for 1 -month minimum duration.

Retrospective age-of-onset reports were used to generate cumulative lifetime prevalence curves for respondents with longest episodes of $1-2,3-5,6-11$, and $\geqslant 12$ months. Although the distributions differ significantly $\left(\chi^{2}{ }_{3}=13 \cdot 0\right.$, $p=0.005)$, they are substantively very similar (Fig. 1). All have the highest slopes in the age range between the early teens and early 30's. All have median ages of onset in the early to mid 20 's. All have few onsets after age 55 .

Other descriptors of illness course are similar across duration subgroups (Table 2). Mean age of onset is somewhat earlier for shorter durations. Mean number of years in episode is significantly higher among cases with 12-month duration (10.4) than shorter durations $(4 \cdot 9-6 \cdot 5$; $\left.F_{1}=13 \cdot 2-58 \cdot 8, p<0 \cdot 001\right)$, but does not differ by episode duration in the range $1-2,3-5$, or 6-11 months $\left(F_{2}=1 \cdot 4, p=0 \cdot 270\right)$. Respondent reports about number of years in an episode were divided by the difference in reported ages of onset and recency to define annual persistence. The mean of this ratio $(0 \cdot 5-0 \cdot 6)$ does not differ substantially with episode duration, although the difference across subgroups is statistically significant $\left(\chi^{2}{ }_{3}=9 \cdot 1, p<0 \cdot 001\right)$. The average number of months in the past year with an episode among 12-month cases also varies predictably with episode duration.

\section{Role impairment}

Episode duration is unrelated to the per cent of days respondents were totally unable to carry out their usual daily activities because of their GAD in the worst month of the past year $\left(13.5-18 \cdot 1 ; F_{3}=0 \cdot 4, p=0.725\right)$ as well as to nine of 12 nested severity responses on the Sheehan Disability Scales (results not shown, but available on request; $\chi^{2}{ }_{3}=2 \cdot 8-6 \cdot 2, p=0 \cdot 104-0 \cdot 416$ ), including impaired work performance $(18 \cdot 6-$ $30 \cdot 2 \%$ severe), personal relationships $(23 \cdot 7-$ $41 \cdot 3 \%$ severe), and social life (32.5-46.3\% severe). The three exceptions are significant associations of duration with severe, moderate, and any impairment in home management $\left(\chi_{3}^{2}=9 \cdot 4-26 \cdot 2, p=0 \cdot 009-0 \cdot 049\right)$, but these are all non-monotonic and do not remain significant when we compare episode durations of 1-5 versus $\geqslant 6$ months $\left(\chi_{1}^{2}=0 \cdot 5-1 \cdot 5, \quad p=0.218\right.$ $0 \cdot 483$ ).

\section{Co-morbidity}

Lifetime GAD has an elevated odds ratio (OR) with each of the other DSM-IV disorders assessed in the NCS-R across the range of GAD duration definitions (Table 3). Ninety per cent of these ORs are significant at the 0.05 level, with a median size of 3.8 and an inter-quartile range (IQR, 25th-75th percentiles) of $2 \cdot 8-5 \cdot 2$. Episode duration is unrelated to size of OR in nearly three-quarters of the comparisons. The most dramatic exception is a very high OR (18.7) of dysthymia with GAD of $>12$ months duration. ORs also vary with duration of GAD for two anxiety disorders [panic disorder and post-traumatic stress disorder (PTSD)] and two other mood disorders (bipolar I disorder and major depressive disorder). In each of these instances, the ORs generally increase with longer GAD episode durations. The increases involving the two anxiety disorders are most evident between durations of $1-5$ and $\geqslant 6$ months, while the increases involving the two mood disorders are monotonic across the range of durations. 
Table 2. Mean age of onset, years with disorder, annual persistence among lifetime cases of DSM-IV generalized anxiety disorder and months in episode in the past 12 months among 12-month cases by maximum episode duration ${ }^{\mathrm{a}}$

\begin{tabular}{|c|c|c|c|c|c|c|c|c|c|c|}
\hline & \multicolumn{8}{|c|}{ Maximum episode duration } & \multirow[b]{3}{*}{$F$ test } & \multirow[b]{3}{*}{$p$} \\
\hline & \multicolumn{2}{|c|}{$1-2$ months } & \multicolumn{2}{|c|}{$3-5$ months } & \multicolumn{2}{|c|}{ 6-11 months } & \multicolumn{2}{|c|}{$\geqslant 12$ months } & & \\
\hline & $\%$ & (s.e.) & $\%$ & (s.E.) & $\%$ & (s.E.) & $\%$ & (s.e.) & & \\
\hline Age of onset & $25 \cdot 9$ & $(0 \cdot 7)$ & $26 \cdot 9$ & $(1 \cdot 2)$ & $29 \cdot 3$ & $(1 \cdot 4)$ & $27 \cdot 8$ & $(0 \cdot 7)$ & $3 \cdot 0 *$ & $0 \cdot 043$ \\
\hline Years with disorder & $5 \cdot 7$ & $(0 \cdot 4)$ & $4 \cdot 9$ & $(0 \cdot 5)$ & $6 \cdot 5$ & $(1 \cdot 0)$ & $10 \cdot 4$ & $(0 \cdot 5)$ & $22 \cdot 6^{*}$ & $<0.001$ \\
\hline Annual persistence ${ }^{\mathrm{b}}$ & $0 \cdot 5$ & $(0 \cdot 0)$ & $0 \cdot 5$ & $(0 \cdot 0)$ & $0 \cdot 5$ & $(0 \cdot 0)$ & $0 \cdot 6$ & $(0 \cdot 0)$ & $9 \cdot 1^{*}$ & $<0.001$ \\
\hline Months in episode ${ }^{c}$ & $2 \cdot 4$ & $(0 \cdot 1)$ & $3 \cdot 9$ & $(0 \cdot 3)$ & $4 \cdot 7$ & $(0 \cdot 4)$ & $9 \cdot 0$ & $(0 \cdot 4)$ & $106 \cdot 7 *$ & $<0.001$ \\
\hline (n) & \multicolumn{2}{|c|}{ (439) } & \multicolumn{2}{|c|}{$(166)$} & \multicolumn{2}{|c|}{$(175)$} & \multicolumn{2}{|c|}{$(412)$} & & \\
\hline
\end{tabular}

${ }^{a}$ Defined using DSM-IV criteria with organic exclusion and diagnostic hierarchy rules, but varying the duration requirement for the longest episode.

b The ratio of number of years with an episode divided by the difference between age of onset and age of most recent episode.

c Months in episode in the past year among 12-month cases.

* Significant difference across the four subgroups at the $0 \cdot 05$ level.

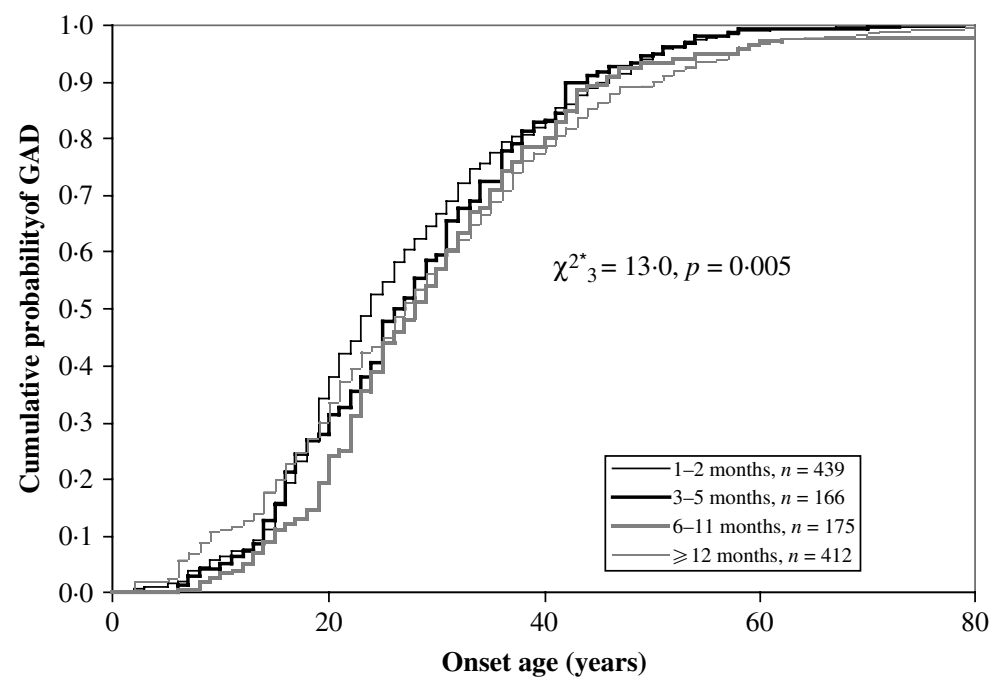

FIG. 1. Cumulative age-of-onset distribution of lifetime DSM-IV generalized anxiety disorder (GAD) by maximum episode duration (defined using DSM-IV criteria with organic exclusion and diagnostic hierarchy rules, but varying the duration requirement for the longest episode). * Significantly different distributions across the four subgroups at the 0.05 level.

\section{Parental history of GAD}

We began the evaluation of parental GAD by focusing on respondents who reported that either none or only one of their parents had GAD and testing whether the gender of the disordered parent was associated with respondent risk and, if so, whether this varied by the gender of the respondent. No evidence of significant gender specificity for parent, respondent, or parent-respondent consistency was found using any of the four minimum duration requirements $\left(\chi^{2}{ }_{1}=0 \cdot 0-3 \cdot 1, \quad p=0 \cdot 080-0 \cdot 829\right)$. We then tested whether respondent risk of GAD differed depending on whether only one versus both parents had a history of GAD. No such evidence was found using any of the four minimum duration requirements $\left(\chi^{2}{ }_{1}=0 \cdot 0-2 \cdot 5\right.$, $p=0 \cdot 111-0 \cdot 853)$. Based on these results, further evaluations included only a single variable for either or both parents having GAD to predict respondent GAD. Parental GAD was 
Table 3. Lifetime co-morbidity $(O R)^{\mathrm{a}}$ of other DSM-IV generalized anxiety disorder $(G A D)$ with other DSM-IV disorders by maximum GAD episode duration ${ }^{\mathrm{b}}$

\begin{tabular}{|c|c|c|c|c|c|c|c|c|c|c|}
\hline & \multicolumn{8}{|c|}{ Maximum episode duration } & \multirow[b]{3}{*}{$\chi^{2}$} & \multirow[b]{3}{*}{$p$} \\
\hline & \multicolumn{2}{|c|}{$1-2$ months } & \multicolumn{2}{|c|}{$3-5$ months } & \multicolumn{2}{|c|}{$6-11$ months } & \multicolumn{2}{|c|}{$\geqslant 12$ months } & & \\
\hline & OR & $(95 \% \mathrm{CI})$ & OR & $(95 \% \mathrm{CI})$ & OR & $(95 \% \mathrm{CI})$ & OR & $(95 \% \mathrm{CI})$ & & \\
\hline \multicolumn{11}{|l|}{ I. Anxiety disorders } \\
\hline Panic disorder & $4 \cdot 5^{*}$ & $(3 \cdot 1-6 \cdot 5)$ & $3 \cdot 6^{*}$ & $(2 \cdot 1-6 \cdot 2)$ & $8 \cdot 3^{*}$ & $(5 \cdot 2-13 \cdot 3)$ & $7 \cdot 3 *$ & $(4 \cdot 9-10 \cdot 8)$ & $8 \cdot 4^{* *}$ & $(0 \cdot 039)$ \\
\hline Agoraphobia (w/o Panic) & $5 \cdot 1 *$ & $(2 \cdot 8-9 \cdot 3)$ & $4 \cdot 1^{*}$ & $(1 \cdot 6-10 \cdot 4)$ & $3 \cdot 8^{*}$ & $(1 \cdot 1-13 \cdot 3)$ & $5 \cdot 9 *$ & $(3 \cdot 6-9 \cdot 8)$ & $0 \cdot 9$ & $(0 \cdot 829)$ \\
\hline Specific phobia & $3 \cdot 6^{*}$ & $(2 \cdot 8-4 \cdot 6)$ & $5 \cdot 0^{*}$ & $(3 \cdot 3-7 \cdot 4)$ & $5 \cdot 0^{*}$ & $(3 \cdot 6-7 \cdot 0)$ & $3 \cdot 4^{*}$ & $(2 \cdot 7-4 \cdot 3)$ & $6 \cdot 2$ & $(0 \cdot 102)$ \\
\hline Social phobia & $5 \cdot 2 *$ & $(4 \cdot 0-6 \cdot 6)$ & $5 \cdot 6^{*}$ & $(3 \cdot 8-8 \cdot 0)$ & $5 \cdot 7 *$ & $(4 \cdot 0-8 \cdot 3)$ & $5 \cdot 3 *$ & $(4 \cdot 3-6 \cdot 7)$ & 0.2 & $(0.971)$ \\
\hline Post-traumatic stress disorder & $3 \cdot 5 *$ & $(2 \cdot 8-4 \cdot 5)$ & $3 \cdot 3 *$ & $(1 \cdot 8-5 \cdot 9)$ & $6 \cdot 4^{*}$ & $(4 \cdot 4-9 \cdot 5)$ & $6 \cdot 5^{*}$ & $(4 \cdot 9-8 \cdot 5)$ & $30 \cdot 2 * *$ & $(<0.001)$ \\
\hline Obsessive-compulsive disorder & $3 \cdot 2 *$ & $(1 \cdot 3-8 \cdot 1)$ & $4 \cdot 5^{*}$ & $(1 \cdot 2-15 \cdot 9)$ & $3.7 *$ & $(1.2-11.8)$ & $4 \cdot 3 *$ & $(2 \cdot 2-8 \cdot 6)$ & 0.3 & $(0.953)$ \\
\hline Any anxiety disorder & $5 \cdot 5^{*}$ & $(4 \cdot 4-6 \cdot 8)$ & $5 \cdot 1 *$ & $(3 \cdot 7-7 \cdot 1)$ & $8 \cdot 6^{*}$ & $(6 \cdot 5-11 \cdot 5)$ & $5 \cdot 7 *$ & $(4 \cdot 7-6 \cdot 9)$ & $9 \cdot 2^{* *}$ & $(0 \cdot 027)$ \\
\hline \multicolumn{11}{|l|}{ II. Mood disorders } \\
\hline Major depressive disorder & $6 \cdot 3 *$ & $(5 \cdot 1-7 \cdot 9)$ & $8 \cdot 2 *$ & $(6 \cdot 0-11 \cdot 0)$ & $10 \cdot 7 *$ & $(7 \cdot 8-14 \cdot 5)$ & $12 \cdot 4 *$ & $(9 \cdot 4-16 \cdot 4)$ & $16 \cdot 0^{* *}$ & $(0 \cdot 001)$ \\
\hline Dysthymia & $3 \cdot 8^{*}$ & $(2 \cdot 6-5 \cdot 7)$ & $2 \cdot 0 *$ & $(1 \cdot 0-4 \cdot 2)$ & $4 \cdot 7 *$ & $(2 \cdot 8-7 \cdot 7)$ & $18 \cdot 7 *$ & $(13 \cdot 6-25 \cdot 8)$ & $85 \cdot 4 * *$ & $(<0 \cdot 001)$ \\
\hline Bipolar I disorder & $4 \cdot 0 *$ & $(2 \cdot 5-6 \cdot 4)$ & $5 \cdot 7 *$ & $(3 \cdot 6-9 \cdot 1)$ & $6 \cdot 9 *$ & $(4 \cdot 3-11 \cdot 0)$ & $9 \cdot 0 *$ & $(5 \cdot 8-14 \cdot 1)$ & $17 \cdot 1 * *$ & $(0 \cdot 001)$ \\
\hline Bipolar II disorder & $4 \cdot 4^{*}$ & $(1 \cdot 4-14 \cdot 0)$ & $1 \cdot 7$ & $(0 \cdot 2-13 \cdot 7)$ & $4 \cdot 8$ & $(0 \cdot 6-38 \cdot 2)$ & $3 \cdot 5$ & $(0 \cdot 7-16 \cdot 7)$ & $0 \cdot 3$ & $(0.960)$ \\
\hline Any mood disorder & $6 \cdot 3 *$ & $(5 \cdot 0-7 \cdot 9)$ & $7 \cdot 9 *$ & $(6 \cdot 0-10 \cdot 5)$ & $10 \cdot 6^{*}$ & $(7 \cdot 6-14 \cdot 6)$ & $14 \cdot 3^{*}$ & $(10 \cdot 7-19 \cdot 3)$ & $20 \cdot 2 * *$ & $(<0 \cdot 001)$ \\
\hline \multicolumn{11}{|l|}{ III. Substance disorders } \\
\hline Alcohol abuse or dependence & $2 \cdot 2 *$ & $(1 \cdot 8-2 \cdot 7)$ & $1.9 *$ & $(1 \cdot 3-2 \cdot 8)$ & $2 \cdot 1^{*}$ & $(1 \cdot 3-3 \cdot 2)$ & $2 \cdot 1^{*}$ & $(1 \cdot 7-2 \cdot 6)$ & $0 \cdot 3$ & $(0 \cdot 960)$ \\
\hline Drug abuse or dependence & $2 \cdot 1 *$ & $(1 \cdot 6-2 \cdot 9)$ & $1 \cdot 9$ & $(0 \cdot 9-3 \cdot 9)$ & $2 \cdot 0^{*}$ & $(1 \cdot 2-3 \cdot 1)$ & $2 \cdot 5 *$ & $(1 \cdot 8-3 \cdot 5)$ & $1 \cdot 6$ & $(0 \cdot 668)$ \\
\hline Any substance disorder & $2 \cdot 0^{*}$ & $(1 \cdot 7-2 \cdot 5)$ & $1 \cdot 9^{*}$ & $(1 \cdot 3-2 \cdot 7)$ & $2 \cdot 1^{*}$ & $(1 \cdot 4-3 \cdot 2)$ & $2 \cdot 1^{*}$ & $(1 \cdot 7-2 \cdot 6)$ & $0 \cdot 4$ & $(0 \cdot 942)$ \\
\hline \multicolumn{11}{|l|}{ IV. Impulse-control disorders } \\
\hline Attention deficit disorder & $2 \cdot 6^{*}$ & $(1 \cdot 8-3 \cdot 9)$ & $3 \cdot 1 *$ & $(1 \cdot 5-6 \cdot 3)$ & $3 \cdot 5^{*}$ & $(1.9-6 \cdot 4)$ & $3 \cdot 6^{*}$ & $(2 \cdot 3-5 \cdot 7)$ & $1 \cdot 5$ & $(0 \cdot 690)$ \\
\hline Oppositional defiant disorder & $2 \cdot 5^{*}$ & $(1 \cdot 8-3 \cdot 6)$ & $3 \cdot 8^{*}$ & $(2 \cdot 4-6 \cdot 1)$ & $1 \cdot 8^{*}$ & $(1 \cdot 0-3 \cdot 1)$ & $2 \cdot 8^{*}$ & $(1 \cdot 6-4 \cdot 8)$ & $5 \cdot 0$ & $(0 \cdot 174)$ \\
\hline Intermittent explosive disorder & $4 \cdot 3 *$ & $(3 \cdot 3-5 \cdot 6)$ & $3 \cdot 0^{*}$ & $(1 \cdot 7-5 \cdot 2)$ & $3 \cdot 4 *$ & $(2 \cdot 0-5 \cdot 8)$ & $3 \cdot 8^{*}$ & $(2 \cdot 8-5 \cdot 2)$ & $2 \cdot 4$ & $(0 \cdot 503)$ \\
\hline Conduct disorder & $1 \cdot 7 *$ & $(1 \cdot 1-2 \cdot 7)$ & $2 \cdot 4^{*}$ & $(1 \cdot 1-5 \cdot 3)$ & $2 \cdot 2^{*}$ & $(1 \cdot 3-3 \cdot 9)$ & $2 \cdot 8^{*}$ & $(1 \cdot 9-4 \cdot 2)$ & $5 \cdot 8$ & $(0 \cdot 123)$ \\
\hline Any impulse disorder & $3 \cdot 5^{*}$ & $(2 \cdot 6-4 \cdot 7)$ & $3 \cdot 8^{*}$ & $(2 \cdot 4-6 \cdot 1)$ & $2 \cdot 7^{*}$ & $(1 \cdot 8-4 \cdot 0)$ & $3 \cdot 4^{*}$ & $(2 \cdot 4-4 \cdot 8)$ & $2 \cdot 3$ & $(0 \cdot 506)$ \\
\hline \multicolumn{11}{|l|}{ V. Any disorder } \\
\hline Exactly one disorder & $0 \cdot 9$ & $(0 \cdot 7-1 \cdot 2)$ & $1 \cdot 2$ & $(0 \cdot 7-2 \cdot 1)$ & $1 \cdot 3$ & $(0 \cdot 8-1 \cdot 9)$ & $0 \cdot 8$ & $(0 \cdot 5-1 \cdot 0)$ & $4 \cdot 7$ & $(0 \cdot 197)$ \\
\hline Exactly two disorders & $2 \cdot 0^{*}$ & $(1 \cdot 4-2 \cdot 7)$ & $2 \cdot 0^{*}$ & $(1 \cdot 1-3 \cdot 5)$ & $2 \cdot 1^{*}$ & $(1 \cdot 3-3 \cdot 5)$ & $2 \cdot 4 *$ & $(2 \cdot 0-3 \cdot 0)$ & 1.9 & $(0 \cdot 602)$ \\
\hline Three or more disorders & $6 \cdot 8^{*}$ & $(5 \cdot 6-8 \cdot 2)$ & $5 \cdot 9 *$ & $(4 \cdot 4-8 \cdot 0)$ & $7 \cdot 9^{*}$ & $(5 \cdot 1-12 \cdot 1)$ & $10 \cdot 2 *$ & $(7 \cdot 9-13 \cdot 5)$ & $8 \cdot 8^{* *}$ & $(0 \cdot 033)$ \\
\hline$(n)^{\mathrm{c}}$ & & $(4945)$ & & $(4674)$ & & $(4682)$ & & $(4921)$ & & \\
\hline
\end{tabular}

a The odds ratios (ORs) were estimated in logistic regression equations with a dummy variable for GAD predicting a dummy variable for the co-morbid disorder, controlling for age of respondent with dummy variables for the following age groups: five-year intervals between $25-29$ and $60-64$ and $\geqslant 65$ years. The age controls were used to adjust for spurious associations between GAD and other disorders due to age differences in lifetime risk of all these disorders, yielding an approximation of the weighted average of the within-year ORs across the full age range of the sample.

b All disorders were defined using DSM-IV criteria with organic exclusion and diagnostic hierarchy rules. The definition of GAD varied the duration requirement for the longest episode.

c The samples used to estimate each of the four equations include respondents with no lifetime GAD $(n=4510)$ plus those in one and only one of the four GAD episode duration subgroups of 1-2 months $(n=435), 3-5$ months $(n=164), 6-11$ months $(n=172)$, or $\geqslant 12$ months $(n=411)$. For example, the 4945 respondents used to estimate the equation for GAD with a duration of 1-2 months include the 4510 with no lifetime GAD plus the 435 having a history of GAD with maximum duration of 1-2 months.

* Significant at the 0.05 level, two-sided test.

** Significant difference of ORs across the four subgroups at the 0.05 level.

a significant predictor of respondent GAD both among females and among males in each of the four duration subgroups, with ORs in the range 2.3-3.4 among females and 3.5-8.6 among males (results not shown, but available on request). No significant difference was found in the ORs depending on respondent episode duration either among females $\left(\chi^{2}{ }_{3}=2 \cdot 0, p=0 \cdot 563\right)$ or males $\left(\chi^{2}{ }_{3}=5 \cdot 6, p=\right.$ $0 \cdot 131)$.

\section{Sociodemographic predictors}

Statistically significant sociodemographic predictors of broadly defined (1-month minimum duration) lifetime GAD include being younger than 60 years, having more than a high school education, having an 'other' occupational status (mostly unemployed and disabled), and being previously married, Non-Hispanic White, and female (results not shown, but available on 
request). Although all these predictors are significant, the ORs are uniformly modest in magnitude $(1 \cdot 3-2 \cdot 3)$. Nested analyses (results not shown, but available on request) showed that four of these six predictors are not significantly related to any of the successively more restrictive definitions of GAD: education $\left(\chi^{2}{ }_{3}=\right.$ $0 \cdot 2-2 \cdot 7, \quad p=0 \cdot 448-0 \cdot 975)$, employment status $\left(\chi_{4}^{2}=2 \cdot 9-5 \cdot 6, \quad p=0 \cdot 231-0.577\right)$, race-ethnicity $\left(\chi^{2}{ }_{3}=1 \cdot 4-5 \cdot 7, \quad p=0 \cdot 129-0.699\right)$, and gender $\left(\chi^{2}{ }_{1}=0 \cdot 1-0 \cdot 2, p=0 \cdot 648-0 \cdot 807\right)$. The association of respondent age with lifetime GAD, in comparison, varies significantly depending on episode duration, with increasingly higher prevalence in the middle age groups (30-44 and 45-59) relative to either the younger (18-29) or older $(\geqslant 60)$ age groups as the duration requirement increases. The association of marital status with lifetime GAD also varies by episode duration, with risk decreasing among the never married and increasing among the previously married relative to the married as the duration requirement increases.

\section{DISCUSSION}

The analyses reported here have two important limitations. First, diagnoses were based on fully structured lay interviews rather than clinician interviews, although clinical reappraisal showed good concordance with the SCID in a random subsample of cases. Second, duration was assessed retrospectively with a single question. No data are available on the accuracy of these retrospective reports. Given the importance of episode duration for these analyses, it is noteworthy that respondent age at interview and retrospectively reported age of onset are both significantly related to reported episode duration. These associations raise the possibility of either recall failure among older respondents with a history of short episodes or progression from shorter to longer episodes with age. The cross-sectional NCS-R design is incapable of capturing either of these dynamic possibilities.

Within the context of these limitations, we found substantively plausible variation in estimates of prevalence by episode duration. Measures of onset and course, in comparison, were quite comparable across subsamples defined in terms of episode duration, although respondents with episodes that persisted for $>12$ months reported more years in episode than respondents with episodes in the 1-11 months range. In addition, consistent with previous research, we found that episode duration was largely unrelated to most measures of impairment, co-morbidity, and sociodemographics (Bienvenu et al. 1998; Maier et al. 2000; Carter et al. 2001). In cases where duration was related to impairment, the associations were non-monotonic. In cases where duration was related to co-morbidity, the ORs generally increased with GAD episode duration, but in ways that were inconsistent across the range of co-morbid disorders (i.e. the $1-5 v$. $\geqslant 6$ month for co-morbid panic disorder and PTSD compared to $1-11 v$. $\geqslant 12$ months for co-morbid dysthymia and associations increasing in roughly linear fashion with duration for other co-morbid mood disorders). We also found that episode duration is not significantly related to parental history of GAD. This finding is indirectly consistent with evidence from twin research that duration of GAD in one co-twin is unrelated to risk of GAD in the other co-twin (Kendler et al. 1994). We also found that episode duration is not strongly related to most sociodemographic correlates with the notable exception of age. In the case of age, as noted above, the possibility exists of either age-related differential recall failure or an association of age with progression from shorter to longer episodes. We are incapable of distinguishing these possibilities with the cross-sectional NCS-R data.

These results support the view that a large number of people exist with a clinically significant GAD-like syndrome that is characterized by episodes of $<6$ months duration (Rickels \& Rynn, 2001). In saying this, the issue of recurrence is one of obvious importance. We found that cases with exclusively short episodes typically recur over a number of years and that the average number of years with an episode is equal to that of cases with episodes that last 6-11 months. In light of this fact, it might be useful for future studies to consider whether episode recurrence should play a more important part than it currently does as a defining feature of GAD. This might be especially useful among cases with exclusively short episodes. It is noteworthy in this regard that the average number of 
months in an episode in the past year among NCS-R respondents with 12-month prevalence whose longest lifetime episodes were in the range 1-2 months was above the upper end of this range $(2.4$ months). This might be interpreted as meaning that respondents with short episodes sometimes have recurrences within a single year. Another plausible possibility, of course, is that these short episodes represent fluctuations in severity among chronic subthreshold cases. Although we are unable to distinguish these two possibilities in the NCS-R data, an attempt to do so should be made in future epidemiological studies.

A question can be raised whether reverting to a 1-month duration requirement would make sense clinically in that treatment might not be necessary for cases with such short durations. This concern should be less, however, for maintenance medication of chronic-recurrent cases. It is not clear from existing trials that currently available treatment would be effective in preventing recurrence of cases with short episode durations, as maintenance therapy trials have been carried out exclusively with cases of longer duration (Pollack et al. 2003). Even if subsequent empirical research shows that currently available therapies are not effective in this way we should not, however, reify this failure by defining the problem out of existence in the upcoming DSM and ICD revisions. Instead, cases with short duration should be included in the diagnostic system in recognition of their clinical significance.

It is not clear whether reverting to a 1-month GAD duration requirement would lead to the same problem as in DSM-III of distinguishing GAD from situational stress reactions. The requirement that the worry must be excessive and hard to control was added to DSM-III-R for precisely this purpose. However, excessiveness is more difficult to assess when focusing only on short-term reactions. In addition, duration is one dimension by which excessive worry is assessed - as indicated either by worry persisting even after the objective life situation that led to the worry resolves or by the extreme worry that often occurs at the onset of an objectively worrisome life situation not decreasing with time in the way it would normally be expected to do.

A deeper issue that drives the concern about distinguishing between GAD and adjustment disorder is that a DSM-IV diagnosis of GAD requires worry to be excessive in relation to objective life situations. Were it not for this requirement, the issue of distinguishing GAD from adjustment disorder would be of considerably less interest, as adjustment disorder would be merely a residual category. However, as it is now patients who meet all other criteria for GAD cannot be diagnosed with GAD if they are exposed to an ongoing life situation that is so objectively worrisome that most people in the situation meet the other criteria for GAD. Adjustment disorder is the default diagnosis unless the patient meets criteria for some other relevant disorder (e.g. PTSD). The 6-month GAD episode duration requirement is thought to be important in a situation of this type to reduce confusion between GAD and adjustment disorder.

It is instructive to compare the ways in which the issues described in the last paragraph play out in the diagnosis of GAD versus the diagnosis of major depression. The important distinction is that the latter diagnosis, unlike GAD, does not hinge on whether dysphoria or anhedonia is considered excessive. Indeed, a distinction is made between endogenous and reactive cases of major depression in order to indicate the role played by objective life situations in episode onset. Because of this greater diagnostic inclusiveness, concerns have not been raised about increasing the 2-week major depression minimum duration requirement to reduce confusion with adjustment disorder. It might be useful to consider why excessive and non-excessive cases of dysphoria and anhedonia are both included in the diagnosis of major depression, while only excessive cases are included in the diagnosis of GAD. The fact that normal grief reactions are excluded from a diagnosis of major depression might be taken to imply that other types of stress reactions are considered not normal (i.e. excessive), but such an interpretation goes well beyond the conventional interpretation of the diagnostic criteria for major depression. While a thorough consideration of the rationale for this lack of parallel between the treatment of the excessiveness requirement for major depression and GAD is outside the scope of the current paper, it is clear from this brief comparison that the legitimacy of the excessiveness requirement for a diagnosis of GAD needs to be addressed in 
future research in order to consider the full implications of changing the current GAD duration requirement.

\section{ACKNOWLEDGMENTS}

The National Comorbidity Survey Replication (NCS-R) is supported by NIMH (U01MH60220) with supplemental support from NIDA, the Substance Abuse and Mental Health Services Administration (SAMHSA), the Robert Wood Johnson Foundation (RWJF; Grant 044708), and the John W. Alden Trust. Additional support for the preparation of this report was provided by Pfizer, Inc. Collaborating investigators include Ronald C. Kessler (Principal Investigator, Harvard Medical School), Kathleen Merikangas (Co-Principal Investigator, NIMH), James Anthony (Michigan State University), William Eaton (The Johns Hopkins University), Meyer Glantz (NIDA), Doreen Koretz (Harvard University), Jane McLeod (Indiana University), Mark Olfson (Columbia University College of Physicians and Surgeons), Harold Pincus (University of Pittsburgh), Greg Simon (Group Health Cooperative), Michael Von Korff (Group Health Cooperative), Philip Wang (Harvard Medical School), Kenneth Wells (UCLA), Elaine Wethington (Cornell University), and Hans-Ulrich Wittchen (Max Planck Institute of Psychiatry).

A complete list of NCS publications and the full text of all NCS-R instruments can be found at http://www.hcp.med.harvard.edu/ncs. Send correspondence to NCS@hcp.med.harvard.edu. The NCS-R is carried out in conjunction with the World Health Organization World Mental Health (WMH) Survey Initiative. We thank the staff of the WMH Data Collection and Data Analysis Coordination Centres for assistance with instrumentation, fieldwork, and consultation on data analysis. These activities were supported by the John D. and Catherine T. MacArthur Foundation, the Pfizer Foundation, the US Public Health Service (R13-MH066849, R01-MH069864, and R01 DA016558), the Pan American Health Organization, Eli Lilly and Company, and GlaxoSmithKline. A complete list of WMH publications and instruments can be found at http://www.hcp.med.harvard.edu/ wmhcidi.
The authors appreciate the helpful comments of Kathleen Merikangas and Bedirhan Ustun on earlier drafts.

\section{DECLARATION OF INTEREST}

None.

\section{NOTE}

Supplementary information accompanies this paper on the Journal's website (http://journals. cambridge.org).

\section{REFERENCES}

APA (1980). Diagnostic and Statistical Manual of Mental Disorders (3rd edn). American Psychiatric Association: Washington, DC.

APA (1987). Diagnostic and Statistical Manual of Mental Disorders (3rd edn revised). American Psychiatric Association: Washington, DC.

APA (1994). Diagnostic and Statistical Manual of Mental Disorders (4th edn). American Psychiatric Association: Washington, DC.

Andreasen, N. C., Endicott, J., Spitzer, R. L. \& Winokur, G. (1977). The family history method using diagnostic criteria: reliability and validity. Archives of General Psychiatry 34, 1229-1235.

Barlow, D. H., Blanchard, E. B., Vermilyea, J. A., Vermilyea, B. B. \& DiNardo, P. A. (1986). Generalized anxiety and generalized anxiety disorder: description and reconceptualization. American Journal of Psychiatry 143, 40-44

Barlow, D. H. \& Wincze, J. (1998). DSM-IV and beyond: what is generalized anxiety disorder? Acta Psychiatrica Scandinavica (Suppl.) 393, 23-29.

Bienvenu, O. J., Nestadt, G. \& Eaton, W. W. (1998). Characterizing generalized anxiety: temporal and symptomatic thresholds. Journal of Nervous and Mental Disease 186, 51-56.

Breier, A., Charney, D. S. \& Heninger, G. R. (1985). The diagnostic validity of anxiety disorders and their relationship to depressive illness. American Journal of Psychiatry 142, 787-797.

Breslau, N. (1985). Depressive symptoms, major depression and generalized anxiety: a comparison of self-reports on CES-D and results from diagnostic interviews. Psychiatry Research 15, 219 229.

Breslau, N. \& Davis, G. C. (1985a). DSM-III generalized anxiety disorder: an empirical investigation of more stringent criteria. Psychiatry Research 15, 231-238.

Breslau, N. \& Davis, G. C. (1985b). Further evidence on the doubtful validity of generlized anxiety disorder. Psychiatry Research 16, 177-179.

Carter, R. M., Wittchen, H. U., Pfister, H. \& Kessler, R. C. (2001) One-year prevalence of subthreshold and threshold DSM-IV generalized anxiety disorder in a nationally representative sample. Depression Anxiety 13, 78-88.

Clayton, P. J., Grove, W. M., Coryell, W., Keller, M., Hirschfeld, R. \& Fawcett, J. (1991). Follow-up and family study of anxious depression. American Journal of Psychiatry 148, 1512-1517.

First, M. B., Spitzer, R. L., Gibbon, M. \& Williams, J. B. W. (2002). Structured Clinical Interview for DSM-IV-TR Axis I Disorders, Research Version, Non-Patient Edition $(S C I D-I / N P)$. Biometrics Research, New York State Psychiatric Institute: New York

Halli, S. S., Rao, K. V. \& Halli, S. S. (1992). Advanced Techniques of Population Analysis. Plenum: New York.

Kendler, K. S., Davis, C. G. \& Kessler, R. C. (1997). The familial aggregation of common psychiatric and substance use disorders in 
the National Comorbidity Survey: a family history study. British Journal of Psychiatry 170, 541-548.

Kendler, K. S., Neale, M. C., Kessler, R. C., Heath, A. C. \& Eaves, L. J. (1994). Clinical characteristics of familial generalized anxiety disorder. Anxiety 1, 186-191.

Kessler, R. C., Berglund, P., Chiu, W. T., Demler, O., Heeringa, S., Hiripi, E., Jin, R., Pennell, B. E., Walters, E. E., Zaslavsky, A. \& Zheng, H. (2004a). The US National Comorbidity Survey Replication (NCS-R): design and field procedures. International Journal of Methods in Psychiatric Research 13, 69-92.

Kessler, R. C., Berglund, P., Demler, O., Jin, R., Koretz, D., Merikangas, K. R., Rush, A. J., Walters, E. E. \& Wang, P. S. (2003). The epidemiology of major depressive disorder: results from the National Comorbidity Survey Replication (NCS-R). Journal of the American Medical Association 289, 3095-3105.

Kessler, R. C., Berglund, P. A., Demler, O., Jin, R. \& Walters, E. E. (in press). Lifetime prevalence and age-of-onset distributions of DSM-IV disorders in the National Comorbidity Survey Replication (NCS-R). Archives of General Psychiatry.

Kessler, R. C., Keller, M. B. \& Wittchen, H.-U. (2001). The epidemiology of generalized anxiety disorder. Psychiatric Clinics of North America 24, 19-40.

Kessler, R. C., McGonagle, K. A., Zhao, S., Nelson, C. B., Hughes, M., Eshleman, S., Wittchen, H.-U. \& Kendler, K. S. (1994). Lifetime and 12-month prevalence of DSM-III-R psychiatric disorders in the United States: results from the National Comorbidity Survey. Archives of General Psychiatry 51, 8-19.

Kessler, R. C. \& Merikangas, K. R. (2004). The National Comorbidity Survey Replication (NCS-R): background and aims. International Journal of Methods in Psychiatric Research 13, 60-68.

Kessler, R. C. \& Ustun, T. B. (2004). The World Mental Health (WMH) Survey Initiative Version of the World Health Organization (WHO) Composite International Diagnostic Interview (CIDI). International Journal of Methods in Psychiatric Research 13, 93-121.

Kessler, R. C., Walters, E. E. \& Wittchen, H.-U. (2004b). Epidemiology. In Generalized Anxiety Disorder: Advances in
Research and Practice (ed. R. G. Heimberg, C. L. Turk and D. S. Mennin), pp. 29-50. Guilford Press: New York.

Leon, A. C., Olfson, M., Portera, L., Farber, L. \& Sheehan, D. V. (1997). Assessing psychiatric impairment in primary care with the Sheehan Disability Scale. International Journal of Psychiatry in Medicine 27, 93-105.

Maier, W., Gansicke, M., Freyberger, H. J., Linz, M., Heun, R. \& Lecrubier, Y. (2000). Generalized anxiety disorder (ICD-10) in primary care from a cross-cultural perspective: a valid diagnostic entity? Acta Psychiatrica Scandinavica 101, 29-36.

Noyes Jr., R., Woodman, C., Garvey, M. J., Cook, B. L., Suelzer, M., Clancy, J. \& Anderson, D. J. (1992). Generalized anxiety disorder vs. panic disorder. Distinguishing characteristics and patterns of comorbidity. Journal of Nervous and Mental Disease 180, 369-379.

Pollack, M. H., Meoni, P., Otto, M. W., Simon, N. \& Hackett, D. (2003). Predictors of outcome following venlafaxine extendedrelease treatment of DSM-IV generalized anxiety disorder: a pooled analysis of short- and long-term studies. Journal of Clinical Psychopharmacology 23, 250-259.

Research Triangle Institute (2002). SUDAAN: Professional Software for Survey Data Analysis [computer program], (Version 8.01). Research Triangle Park, NC.

Rickels, K. \& Rynn, M. (2001). Overview and clinical presentation of generalized anxiety disorder. Psychiatric Clinics of North America 24, 1-17.

Wittchen, H.-U., Zhao, S., Kessler, R. C. \& Eaton, W. W. (1994) DSM-III-R generalized anxiety disorder in the National Comorbidity Survey. Archives of General Psychiatry 51, 355364.

Wolter, K. M. (1985). Introduction to Variance Estimation. SpringerVerlag: New York.

WHO (1992). The ICD-10 Classification of Mental and Behavioral Disorders: Clinical Descriptions and Diagnostic Guidelines. WHO: Geneva.

WHO (1993). The ICD-10 Classification of Mental and Behavioral Disorders: Diagnostic Criteria for Research. WHO: Geneva. 